\title{
Educação em Direitos Humanos e Promoção da Igualdade Racial
}

\author{
Paulo Vinicius Baptista da Silva \\ Universidade Federal do Paraná \\ Débora Cristina de Araújo \\ Universidade Federal do Paraná
}

\section{Resumo}

Esse artigo se propõe a discutir possíveis formas de articulação da Educação em Direitos Humanos no Brasil com políticas de promoção de igualdade étnico-racial. Para tal, discute pontos específicos do PNEDH, articulando com outras normativas importantes, em alguns casos o PNDH em suas diferentes versões, em outros com normativas específicas de promoção de igualdade racial, como o artigo 26A da LDB e a Carta de Durban. Conclui pela implantação de uma educação aberta para o diálogo constante sobre e com as diferenças e exercitando o diálogo permanente com movimentos sociais.

Palavras-chave: Educação em direitos humanos. Racismo. Relações étnico-raciais. 


\section{Human rights education and the promotion of racial equality}

The aim of this article is to discuss possible ways of articulation between human rights education in Brazil and policies to promote ethnic and racial equality. To this end, we discuss specific points of the National Program on Human Rights Education (PNEDH), linking it with other major policies and some specific regulations for the promotion of racial equality, such as the article 26 of the Brazilian Education Act (LDB) and the Letter from Durban. The article concludes in support of the implementation of an education open to constant discussion about differences and in permanent dialogue with social movements.

Keywords: Human rights education. Racism. Ethnic relations.

\section{Educación en Derechos Humanos y la promoción de la igualdad racial}

Este artículo tiene como objetivo discutir posibles formas de articular la educación en derechos humanos en Brasil con políticas de promoción de la igualdad étnica y racial. Con este fin, se discute el Programa Nacional de Educación en Derechos Humanos (PNEDH) y su vinculación con el Programa Nacional de Derechos Humanos (PNDH) así como con algunas de las normas específicas para la promoción de la igualdad racial. Se llega a la conclusión sobre la necesidad de una educación abierta al diálogo sobre y con las diferencias, como también el ejercicio de un diálogo permanente con los movimientos sociales.

Palabras clave: Educación en derechos humanos. Racismo. Relaciones étnico-raciales. 


\section{Educação em Direitos Humanos e Promoção de Igualdade Racial}

Esse artigo se propõe a discutir possíveis formas de articulação da Educação em Direitos Humanos no Brasil com políticas de promoção de igualdade racial. Partimos de uma reflexão sobre o conceito de raça, que teve no racismo, dito científico, uma atribuição biologizante, mas que contemporaneamente prescinde da biologia cada vez mais. Ainda que não tendo fundamento biológico, raça tem operado socialmente estabelecendo hierarquias e espaços sociais para determinados grupos de pessoas. Consideramos que a plena existência de raça como construção social relaciona-se a um processo que denominamos de 'racialização': a partir de características reais ou imputadas a um grupo social esse tem, sistematicamente, acesso negado ou dificultado a bens materiais ou simbólicos.

0 processo denominado racialização implica que, ao ser tratado como inferior, o grupo social racializado passa a ter o acesso a bens e materiais simbólicos privados ou dificultados fazendo com que raça, mesmo não existindo como diferença biológica, exista do ponto de vista social. Ou seja, ao se tratar sistematicamente determinados grupos sociais como inferiores, as raças tornam-se plenas de existência social. Reconhecemos que o racismo é um fenômeno que ocorre em diferentes contextos, sendo sempre aviltante e inaceitável. São diversos os exemplos de países, na contemporaneidade ou não, em que a racialização manifesta-se em distintos contextos sociais e muitas vezes prescinde da aparência. Por exemplo, os italianos foram racializados na Suiça no século XIX, tendo acesso negado a bens materiais e simbólicos e sendo considerados pelos suíços como "porcos/sujos" e "burros/débeis mentais", figurando em uma série de canções populares e piadas com tais sentidos estigmatizantes (Johler, 1996), em um processo social que determinou uma inserção "marginal" dos italianos na sociedade suíça e impediu a integração e mobilidade social desse grupo.

As ideias racistas, mesmo após as críticas ao racismo científico posteriores ao holocausto da segunda guerra mundial, continuaram atuantes a ponto de pesquisadores de países em continentes diversos (por exemplo, Harris, 1999; Morrison, 2002 nos EUA; Wieviorka, 2000, na Europa; Coetzee, 1999, na África do Sul; Ramos, 1954; Fernandes, 1964; Nascimento, 2002; Munanga, 2004, no Brasil) apontarem não somente a permanência de tais ideias como também sua forte atuação social, em diferentes contextos, para classificar e inferiorizar determinados grupos sociais. Portanto, torna-se corrente o uso do termo racialização para falar de tais processos de transformação de grupos sociais específicos em raças. Caso observemos as análises do novo racismo na Europa iremos encontrar uma tendência à racialização mais acentuada de grupos específicos em países específicos (turcos e seus descendentes na Alemanha; romenos na Áustria; 
albaneses na Itália; marroquinos na Espanha), aliada a uma tendência geral de racializar imigrantes de países de fora da comunidade europeia que não gozem de alto prestígio internacional. Estadunidenses, canadenses e suíços, por exemplo, não são racializados e não entram na categoria racial "extracomunitário" utilizada na Itália contemporânea (Dal Lago, 1999).

Alguns exemplos foram tomados somente como ilustração de que o racismo e a racialização são fenômenos mundiais, mas passemos ao contexto brasileiro. Quais grupos têm sistematicamente tratamento inferiorizante, cujo acesso a bens sociais e pessoais é dificultado ou impedido no Brasil? Perguntando de outra forma, quais grupos são racializados no país?

Analisando os diversos documentos relacionados aos Direitos Humanos no Brasil teremos a resposta. Por exemplo, nas três versões do Programa Nacional de Direitos Humanos (Brasil, 1996; 2002a; 2010) observam-se nas propostas de ações governamentais uma série de itens relativos à população negra, a sociedades indígenas e a ciganos. Negros/as, indígenas e ciganos/as são, portanto, os grupos que têm sistematicamente acesso negado a bens materiais e simbólicos no Brasil, a ponto de necessitarem de amparo específico na legislação e propostas de ações relativas aos direitos humanos. Interpretamos que essas manifestações em tais documentos nos dão a resposta: são estes os grupos que em diversos contextos recebem tratamento diferenciado baseado em suposto pertencimento a raças. São, conforme o conceito apresentado, os grupos racializados no país.

No que se refere à racialização de negros/as no Brasil contemporâneo, foco mais direto deste texto, assumimos a hipótese de que esse processo relaciona-se a um fenômeno mais amplo de racialização que, ao mesmo tempo em que se expressa com particularidades (o racismo à brasileira), vai muito além das fronteiras tupiniquins e tem raízes históricas profundas. Na contemporaneidade, expressa-se de forma indubitável na Europa, nas Américas e Caribe e na própria África. Ou seja, o racismo, outrora considerado científico, é desacreditado na ciência, mas continua orientando o imaginário ocidental de forma perseverante, em especial as ideias de racionalidade como característica típica europeia, e de sua ausência, que alimenta as ideias de primitivo, incivilizado, rude/rudimentar, corpo e sensação.

As desigualdades no acesso a bens materiais e a bens simbólicos relacionam-se (de forma assíncrona, não-linear) com tais hierarquias raciais e se expressam na educação escolar pelo etnocentrismo e pela organização curricular numa lógica eurocêntrica. No plano das políticas curriculares, este imaginário racialmente hierarquizado tem sido objeto de análise e críticas. Na perspectiva de estudo das políticas educacionais, à qual este artigo se articula, adotamos a opção de examinar a educação em seus 
contextos históricos e como parte do tecido social e político, focalizando os processos culturais pelos quais determinados discursos mantêm-se hegemônicos (Apple, 1996, 2001; Giroux, 1999; Mclaren, 1997). 0 currículo é compreendido como parte de uma tradição seletiva que, por sua vez, compondo a política cultural da educação, considera objetivos econômicos e valores; papel do estado; política cultural e de diferença e identidade; visões de gênero, raça e relações de classe (Apple, 2001). Como expressão de seleções de conteúdos determinadas, os currículos muitas vezes operam numa lógica colonial. Mudanças curriculares no sentido de inserir outros discursos para o centro do trabalho pedagógico operariam numa lógica de descolonização dos currículos.

Apresentadas tais informações conceituais, passamos a um duplo exercício. Discutiremos pontos específicos do Plano Nacional de Educação em Direitos Humanos (PNEDH) articulados com outras normativas importantes, em alguns casos o Programa Nacional de Direitos Humanos (PNDH) em suas diferentes versões, em outros com normativas específicas de promoção de igualdade racial, trazendo para discussão aspectos relacionados aos grupos racializados, com foco na população negra e particularmente suas relações com a Educação. Conforme a apresentação do Plano,

Ao mesmo tempo em que aprofunda questões do Programa Nacional de Direitos Humanos, o PNEDH incorpora aspectos dos principais documentos internacionais de direitos humanos dos quais o Brasil é signatário, agregando demandas antigas e contemporâneas de nossa sociedade pela efetivação da democracia, do desenvolvimento, da justiça social e pela construção de uma cultura de paz. (Brasil, 2006, p. 9).

Em função das limitações deste artigo não serão apresentados de forma pormenorizada os aspectos específicos de documentos internacionais relativos à promoção de igualdade racial e combate ao racismo dos quais o país é signatário. Alguns pontos de documentos específicos serão apresentados e discutidos, em especial da Carta de Durban, ao passo que outros somente citados ou apontados'.

1. Para mais informações, ver, por exemplo: Piovesan (2005) e o Estatuto da Igualdade Racial (Lei 12.288/2010), disponível em: <http://www.planalto.gov.br/ccivil_03/_Ato2007-2010/2010/Lei/L12288.htm>. Acesso em: 25/08/2011. 


\section{PNEDH e relações étnico-raciais ${ }^{2}$}

No PNEDH observa-se uma primeira alusão às relações étnico-raciais em parte da Introdução:

Esse traço conjuntural resulta da conjugação de uma série de fatores, entre os quais cabe destacar: [...] cl a adoção do princípio de empoderamento em benefício de categorias historicamente vulneráveis (mulheres, negros(as), povos indígenas, idosos(as), pessoas com deficiência, grupos raciais e étnicos, gays, lésbicas, bissexuais, travestis e transexuais, entre outros). (Brasil, 2006, p. 15)

Que significa esse princípio de empoderamento de grupos étnico-raciais vulneráveis? Para a escola tem significado duplo: 1) inserir no currículo conteúdos e formas de valorização da população negra, indígena e cigana; 2) nesse processo, priorizar a dialogicidade com os movimentos sociais e culturais que têm trajetórias específicas de defesa de direitos e lutas por emancipação.

0 primeiro ponto está explicitado em outra parte do PNEDH, que será tratada a seguir. No segundo ponto temos a busca de diálogo com movimentos sociais que pode ser realizada de formas diversas. Uma primeira alternativa é o diálogo direto: existem organizações de movimento social negro, de movimento indígena ou associações de ciganos na comunidade onde está a escola? Caso sim, o diálogo pode ser efetivado de formas diversas, considerando as particularidades da escola e dos/as alunos/as, níveis e modalidades de ensino. A participação em eventos e datas comemorativas pode ser uma estratégia, mas uma relação de diálogo deve ir além de conversas pontuais em eventos comemorativos. Entrevistas realizadas por alunos/as, estudo de documentos das organizações, grupos de discussão sobre os temas abordados pelos movimentos sociais, por exemplo, são formas de manter o trabalho para além das datas específicas. 0 intuito é que o conhecimento acumulado, as propostas e reivindicações dos movimentos sociais sejam tratados como conteúdos escolares de alta relevância. Além dos movimentos sociais, os grupos de cultura também podem ser o ponto de apoio e diálogo para o trabalho. 0 empoderamento, nesses casos, significa que a escola poderá articular-se aos grupos e oferecer espaço de trabalho conjunto. A escola pode dar continuidade pelo trabalho com conteúdos relativos a tais manifestações. Os resultados serão em dois sentidos: valorização dos movimentos sociais e valorização da diversidade étnicoracial na escola, ponto também expresso no PNEDH. Citando o Programa Mundial de Educação em Direitos Humanos (PMEDH), observam-se aproximações com a mesma

2. Uma versão anterior deste tópico também foi publicada em Silva (2010). 
temática no que se refere aos objetivos balizadores: “[...] c) fomentar o entendimento, a tolerância, a igualdade de gênero e a amizade entre as nações, os povos indígenas e grupos raciais, nacionais, étnicos, religiosos e linguísticos" (Brasil, 2006, p. 17).

No trecho em questão apontamos uma perspectiva que consideramos restrita, pelo uso do conceito de tolerância (que se repete por diversas outras partes do documento). 0 termo tem sentido de aturar, e não de reciprocidade, e ao definir que se deve ser tolerante define um outro, define uma hierarquia e raciliza esse outro. Por outro lado, o mesmo trecho afirma o necessário fomento à igualdade e à amizade entre os grupos raciais.

No que se refere à Educação Básica, o PNEDH destaca que:

São princípios norteadores da educação em direitos humanos na educação básica: [...] d) a educação em direitos humanos deve estruturar-se na diversidade cultural e ambiental, garantindo a cidadania, o acesso ao ensino, permanência e conclusão, a equidade létnico-racial, religiosa, cultural, territorial, físico-individual, geracional, de gênero, de orientação sexual, de opção política, de nacionalidade, dentre outras) e a qualidade da educação [...]. (Brasil, 2006, p. 23-24).

Nesse sentido, são vários aspectos complexos: 1) o exercício do respeito às diferenças étnico-raciais; 2) a estruturação da Educação na diversidade cultural; 3) o estabelecimento de equidade étnico-racial. Sobre o primeiro ponto necessário se faz conhecer apropriadamente o contexto das relações raciais no Brasil e algumas particularidades no que se refere às populações negra, indígena e cigana. 0 Brasil é um país que apresenta grande complexidade em abordagem da temática racial em função de como o processo de racialização ocorreu. 0 racismo à brasileira organizase como um racismo repleto de ambiguidades, que se afirma na sua negação. Em outras palavras: uma estratégia de dominação racial que foi hegemônica no Brasil era a afirmação de que não existiria racismo no país. Esse conjunto de ideias ficou conhecido como mito da democracia racial, concepção de uma suposta convivência harmoniosa entre os grupos raciais. E tal concepção continua recorrente nos dias de hoje em diversos espaços e contextos. Numa situação de convivência, quando alguma questão racial se coloca, a complexa ética das relações raciais no Brasil nos ensina que é melhor não tocar no assunto. A lógica seria: já que o racismo não existe no Brasil, melhor não mencioná-lo sob pena de fomentar um fenômeno social que não atinge a sociedade brasileira. Portanto, na negação e no silêncio o racismo brasileiro afirma-se. Assim, ao romper o silêncio promove-se um movimento contrário: de explicitação por meio do debate crítico sobre o racismo e sua possível superação.

O segundo ponto abordado, a estruturação da Educação na diversidade cultural, relaciona-se com as proposições de adotar uma proposta curricular calcada no multi- 
culturalismo crítico (Giroux, 1999). 0 termo diversidade tem usos muito distintos e muitas vezes é compreendido de forma a mascarar desigualdades raciais e sociais. Numa acepção crítica, a proposição é que a diversidade é meta de reconfiguração de distribuição de poder numa sociedade estruturalmente desigual. Outro aspecto da citação do PNEDH relaciona-se com proposições de ações programáticas para a Educação Básica, em específico a proposta de inclusão, no currículo escolar, da temática relativa à raça e à etnia (Brasil, 2006, p. 24).

Para tanto, a inserção da temática étnico-racial no currículo relaciona-se com o tratamento na escola como efeito de ações conjuntas e articuladas. E, para realizá-lo, nos parece significativo o trabalho balizado por outros documentos importantes:

- Lei 10.639/03, posteriormente alterada pela Lei 11.645/08 que modificou o artigo 26-A da Lei de Diretrizes e Bases da Educação Nacional para incluir no currículo oficial da rede de ensino a obrigatoriedade da temática História e Cultura AfroBrasileira e Indígena;

- Diretrizes Curriculares Nacionais para a Educação das Relações Étnico-Raciais e para o Ensino de História e Cultura Afro-Brasileira e Africana (Resolução n ${ }^{0}$ 01/04 e Parecer $n^{\circ}$ 03/04 do Conselho Nacional de Educação - CNE);

- Plano Nacional de Implementação das Diretrizes Curriculares Nacionais para Educação das Relações Étnico-Raciais e para o Ensino de História e Cultura Afrobrasileira e Africana (2009).

Tais documentos demandam leitura completa e detalhada, sendo somente alguns pontos específicos aqui abordados. 0 Parecer $n^{\circ} 03 / 04$ do CNE afirma que "as formas de discriminação de qualquer natureza não têm o seu nascedouro na escola, porém o racismo, as desigualdades e a discriminações correntes na sociedade perpassam por ali" (Brasil, 2004, p. 9). Como forma de combater o racismo e a discriminação racial, propõe a "educação das relações étnico-raciais" vinculada com reestruturação curricular: o ensino de conteúdos sobre os processos de discriminação racial existentes no Brasil; a busca da superação do etnocentrismo europeu que estrutura as mentalidades; a articulação com os movimentos sociais, em especial com movimentos negros; o ensino de História e cultura afro-brasileira e africana. Sobre esse último ponto, o referido documento afirma que:

[...] a obrigatoriedade de inclusão de História e Cultura Afro-Brasileira e Africana nos currículos da Educação Básica trata-se de decisão política, com fortes repercussões pedagógicas, inclusive na formação de professores. [...] É importante destacar que não se trata de mudar um foco etnocêntrico marcadamente de raiz europeia por um africano, mas de ampliar o foco nos currículos escolares para a diversidade cultural, racial, social e econômica brasileira. Nesta perspectiva, cabe às escolas incluir no contexto dos 
estudos e atividades, que proporciona diariamente, também as contribuições históricoculturais dos povos indígenas e dos descendentes de asiáticos, além das de raiz africana e européia. (Brasil, 2004, p. 13).

0 próprio Parecer $n^{\circ}$ 03/04 CNE, portanto, adianta-se em relação à modificação na LDB determinada pela Lei 11.645/08 no que se refere ao ensino de conteúdos relativos às contribuições indígenas para o país. Esse ensino direciona-se na proposição de uma Educação para o respeito, como previsto no PNEDH, isto é, na direção de romper com a perspectiva etnocêntrica europeia apontada pelo Parecer $n^{0}$ 03/04 CNE. A proposição implícita no novo texto do artigo 26-A da LDB é que para todos/as os/as alunos/as brasileiros/as são necessários conhecimentos mais elaborados e adequados sobre as culturas e história dos povos indígenas, como também sobre história e cultura afrobrasileira e africana.

No caso dos povos indígenas, as proposições de políticas educacionais têm buscado aprofundar o diálogo com as demandas dos seus movimentos organizados propondo uma política dupla: para o sistema educacional como um todo, estudos mais apropriados e elaborados de História e Cultura Indígena e sua importância para a formação do Brasil e, para os povos indígenas, uma Educação Escolar Indígena, assim caracterizada:

[...] pela afirmação das identidades étnicas, pela recuperação das memórias históricas, pela valorização das línguas e conhecimentos dos povos indígenas, pela vital associação entre escola/sociedade/identidade, e em consonância com os projetos societários definidos autonomamente por cada povo indígena. 0 exercício, no dia-a-dia, de professores, lideranças e seus aliados para a ressignificação da instituição escola - modelada historicamente pela negação da diversidade sociocultural - em um espaço de construção de relações interétnicas orientadas para a manutenção da pluralidade cultural, pelo reconhecimento de diferentes concepções pedagógicas e pela afirmação dos povos indígenas como sujeitos de direitos, sugeriu as diretrizes político-pedagógicas da interculturalidade, do bilinguismo/multilinguismo, da diferenciação, da especificidade e da participação comunitária, formando consensos sobre como seria uma educação escolar protagonizada pelos povos indígenas e associada a seus próprios projetos societários. (Brasil, 2009a).

Essa definição foi transcrita do documento final da I Conferência de Educação Escolar Indígena, realizada em 2009, quando ocorreram discussões em 1.836 escolas indígenas e, em sequência, 18 conferências regionais e a conferência nacional. 0 acesso à educação continua como um problema e um processo de distribuição muito desigual de recursos. Por outro lado, nos anos recentes observa-se um incremento na Educação dos povos indígenas e o referido documento propõe a criação de um Sistema Próprio de Educação 
Escolar Indígena, definida como tendo ordenamento jurídico específico, sob a coordenação do MEC e "[...] com a garantia do protagonismo dos povos indígenas em todos os processos" (Brasil, 2009a, p. 4). Essa proposição relaciona-se com uma percepção que dirige a abordagem do artigo: de que os Direitos Humanos e sua Educação necessitam manter, numa acepção crítica, permanente diálogo com os movimentos sociais como ponto de partida.

No que se refere ao PNEDH, as propostas estão nas ações programáticas para a Educação Básica, relativas ao desenvolvimento de políticas públicas de Educação em Direitos Humanos para povos indígenas, comunidades quilombolas, populações de áreas rurais e ribeirinhas (Brasil, 2006, p. 25).

No caso da população negra, as proposições para comunidades quilombolas aproximamse mais da perspectiva de sistema diferenciado. No documento final da Conferência Nacional de Educação (CONAE) algumas proposições relativas à Educação Quilombola são:

a) Garantir a elaboração de uma legislação específica para a educação quilombola, com a participação do movimento negro quilombola, assegurando o direito à preservação de suas manifestações culturais e à sustentabilidade de seu território tradicional [...] f] Garantir aos professores/as quilombolas a sua formação em serviço e, quando for o caso, concomitantemente com a sua própria escolarização. g) Instituir o Plano Nacional de Educação Quilombola, visando à valorização plena das culturas das comunidades quilombolas, a afirmação e manutenção de sua diversidade étnica. h) Assegurar que a atividade docente nas escolas quilombolas seja exercida preferencialmente por professores/as oriundos/as das comunidades quilombolas. (Brasil, 2010, p. 131-132).

Embora seja possível identificar relativa movimentação recente e alguns investimentos em políticas públicas de forma articulada com uma relação de diálogo com as comunidades, as décadas e séculos de descaso e ausência de políticas públicas são responsáveis por ainda estabelecerem um quadro de omissão do Estado brasileiro no que se refere à garantia de direitos sociais básicos como o próprio acesso à educação (Leite, 2008, p. 972).

Outro aspecto a ser abordado no tocante à Educação e Direitos Humanos trata-se da ampliação do ensino superior como forma de superação de desigualdades tanto sociais quanto raciais. E no PNEDH verifica-se uma ênfase em elementos que coadunam com uma proposta de superação de desigualdades:

Concepção e princípios: 0 Programa Mundial de Educação em Direitos Humanos IONU, 2005), ao propor a construção de uma cultura universal de direitos humanos por meio do conhecimento, de habilidades e atitudes, aponta para as instituições de ensino supe- 
rior a nobre tarefa de formação de cidadãos(ãs) hábeis para participar de uma sociedade livre, democrática e tolerante com as diferenças étnico-racial, religiosa, cultural, territorial, físico-individual, geracional, de gênero, de orientação sexual, de opção política, de nacionalidade, dentre outras. [...] No ensino, a educação em direitos humanos pode ser incluída por meio de diferentes modalidades, tais como, disciplinas obrigatórias e optativas, linhas de pesquisa e áreas de concentração, transversalização no projeto político-pedagógico, entre outros.

Ações programáticas: [...] 18. Desenvolver políticas estratégicas de ação afirmativa que possibilitem a inclusão, o acesso e a permanência de pessoas com deficiências, segmentos geracionais e étnico-raciais, de gênero, de orientação sexual e religiosa, dentre outros nas IES. (Brasil, 2006, p. 27-29).

É possível, portanto, identificar duas questões principais: 1) a formação para a diversidade, que tem como pilar a Educação em Direitos Humanos a ser ministrada nas universidades de diferentes formas - pode ser acrescida, também com as diferentes modalidades listadas, a Educação das Relações Étnico-Raciais nas universidades, em especial nos cursos de formação de professores/as, conforme apontado no Parecer n 03/2004-; 2) o desenvolvimento de políticas de ação afirmativa que modifiquem o perfil de universidade - ainda excludente - para um modelo inclusivo de segmentos estigmatizados, entre os quais os grupos étnico-raciais.

Esse segundo ponto remete à questão do necessário estabelecimento de igualdade étnico-racial, nesse caso na educação superior. A universidade brasileira apresentou uma expansão significativa a partir dos anos 1960, mas de forma muito segregada do ponto de vista étnico-racial. Em 1960, para a população acima de 25 anos, a diferença entre brancos/as e negros/as (categorias pretos e pardos do IBGE agrupadas) com curso superior completo era de 1,3 pontos percentuais, passando a 8,3 pontos em 1999 (Telles, 2003, p. 203).

A demanda por políticas afirmativas no ensino superior inicia-se com a reivindicação do movimento negro brasileiro sobre reserva de vagas para negros/as em universidades e escolas técnicas, que data de 1948 (Quilombo, 1948, p. 3). Nos anos 1980 surgiu com nova intensidade e o então Deputado Federal Abdias no Nascimento ${ }^{3}$ apresentou

3. Abdias do Nascimento (1914-2011) teve sua atuação política marcada pela intensa luta contra a discriminação racial e pela superação das baixas condições socioeconômicas da população negra no Brasil. Como ator, diretor e dramaturgo, Abdias foi um dos responsáveis por fortalecer a identidade negra nas artes cênicas, bem como desenvolver formação escolar para negros/as por meio da criação de cursos de alfabetização. Como parlamentar, assumiu uma postura afirmativa frente às discussões raciais no Brasil e apresentou proposições legais que influenciaram grande parte dos documentos atuais de promoção da igualdade racial. Também foi artista plástico, professor universitário e um dos maiores representantes do pan-africanismo no Brasil. 
o Projeto de Lei (PL) 1.332 de 1983, que versava sobre "ações compensatórias" para a população negra, entre as quais políticas de cotas no ensino superior e mercado de trabalho. Na Assembleia Constituinte novas propostas foram apresentadas, mas o texto aprovado da constituição apenas incorporou as cotas para deficientes no mercado de trabalho. Em 1995 ocorreu uma grande mobilização dos movimentos negros para a Marcha Zumbi dos Palmares contra o racismo, pela cidadania e a vida. 0 pronunciamento da Presidência da República, ao receber a marcha, reconheceu que o Brasil é um país no qual a discriminação racial é estrutural e institucional, demandando, portanto, ações do Estado para combater as desigualdades raciais. A implantação de políticas afirmativas para negros/as e indígenas passou, a partir do final dos anos 1990 , a ser reivindicada com maior intensidade. Foram importantes nesse processo os diversos eventos relacionados com a preparação para a III Conferência Mundial das Nações Unidas contra o Racismo, Discriminação Racial, Xenofobia e Intolerância Correlata (realizada em Durban, em 2001). Nos eventos preparatórios eclodiram com grande força as reivindicações de políticas afirmativas como forma de restituir a igualdade de oportunidades (Silvério, 2001). No relatório do comitê nacional para a preparação da participação brasileira na III Conferência, uma das propostas anotadas foi a "adoção de cotas ou outras medidas afirmativas que promovam acesso de negros às universidades públicas" (Brasil, 2001). No PNDH II, aprovado em 2002, a proposta relativa ao ensino superior ganhou a seguinte redação: "estabelecer mecanismos de promoção da equidade de acesso ao ensino superior, levando em consideração a necessidade de que o contingente de alunos universitários reflita a diversidade racial e cultural da sociedade brasileira" (Brasil, 2002, p. 36).

Também o PNDH III oferece elementos que convergem com o reconhecimento de políticas afirmativas, como aponta o eixo orientador Universalizar Direitos em um Contexto de Desigualdades:

0 combate à discriminação mostra-se necessário, mas insuficiente enquanto medida isolada. Os pactos e convenções que integram o sistema internacional de proteção dos Direitos Humanos apontam para a necessidade de combinar estas medidas com políticas compensatórias que aceleram a construção da igualdade, como forma capaz de estimular a inclusão de grupos socialmente vulneráveis. Além disso, as ações afirmativas constituem medidas especiais e temporárias que buscam remediar um passado discriminatório. No rol de movimentos e grupos sociais que demandam políticas de inclusão social encontram-se crianças, adolescentes, mulheres, pessoas idosas, lésbicas, gays, bissexuais, travestis, transexuais, pessoas com deficiência, povos indígenas, populações negras e quilombolas, ciganos, ribeirinhos, varzanteiros, pescadores, entre outros. (Brasil, 2010, p. 53). 
Após 1995, com a demanda por políticas afirmativas na pauta, a reação de parte da sociedade civil, por meio de intelectuais e de meios de comunicação de massa, foi largamente contrária à adoção de formas de discriminação positiva. Mesmo assim, as posições do Brasil na conferência de Durban, reconhecendo de forma incontestável as desigualdades raciais no país e se comprometendo a revertê-las por meio de políticas afirmativas, repercutiu muito favoravelmente no plano internacional e auxiliou a antepor resistências internas, ainda que atualmente tal debate continue sendo palco de conflitos. Vários segmentos da administração pública, como os Ministérios da Justiça e da Reforma Agrária, passaram então a adotar cotas de emprego para negros/as.

Na Declaração e Programa de Ação adotados na III Conferência Mundial de Combate ao Racismo, Discriminação Racial, Xenofobia e Intolerância Correlata (Carta de Durban) destaca-se a proposição a seguir:

99. Reconhece que o combate ao racismo, discriminação racial, xenofobia e intolerância correlata é responsabilidade primordial dos Estados. Portanto, incentiva os Estados a desenvolverem e elaborarem planos de ação nacionais para promoverem a diversidade, igualdade, equidade, justiça social, igualdade de oportunidades e participação para todos. Através, dentre outras coisas, de ações e de estratégias afirmativas ou positivas; estes planos devem visar a criação de condições necessárias para a participação efetiva de todos nas tomadas de decisão e o exercício dos direitos civis, culturais, econômicos, políticos e sociais em todas as esferas da vida com base na não-discriminação.

No período pós-Durban as propostas de ação afirmativa no ensino superior conseguiram avançar com passos importantes, inicialmente em algumas universidades estaduais. No governo do Estado do Rio de Janeiro as propostas dos movimentos negros tiveram como interlocutora a então vice-governadora Benedita da Silva. Em novembro de 2001 o governo desse Estado sancionou uma lei que estabeleceu reserva de no mínimo 40\% de vagas nas universidades estaduais cariocas (Universidade do Estado do Rio de Janeiro e Universidade Estadual do Norte Fluminense) para estudantes negros/as. Em 2002, a Universidade Estadual da Bahia (UNEB) estabeleceu a reserva de $40 \%$ de suas vagas para estudantes negros/as e a Universidade Estadual do Mato Grosso do Sul (UEMS) aprovou reserva de 10\% das vagas para estudantes indígenas (com um grande programa de permanência e garantia de bolsa para todos os alunos indígenas) e 20\% para estudantes negros/as. Em 2003, pela primeira vez uma universidade federal, a Universidade de Brasília (UnB), adotou a reserva de $20 \%$ de vagas para alunos/as negros/as e 10 vagas suplementares anuais para estudantes indígenas. Em novembro do mesmo ano a Universidade Federal de Alagoas (UFAL) aprovou sistema de reserva de $20 \%$ das vagas para alunos/as negros/as. No ano seguinte, instituíram 
novos programas de reservas de vagas a Universidade Federal da Bahia (UFBA) e a Universidade Federal do Paraná (UFPR). A UFBA instituiu reserva de $43 \%$ das vagas para estudantes oriundos/as da escola pública, das quais $85 \%$ são reservadas para negros/as (aproximadamente $37 \%$ do total de vagas), outros $2 \%$ são reservados para índios-descendentes lalém disso, cada curso oferece duas vagas para índios/as aldeados/as ou quilombolas). A UFPR reserva, na segunda fase do exame vestibular, 20\% de vagas para estudantes de escola pública, $20 \%$ para negros/as. Para indígenas, são 10 vagas anuais a serem preenchidas através de processo seletivo específico, segundo demanda intermediada pela Fundação Nacional do Índio (FUNAll. As avaliações realizadas até então apresentaram dados bastante positivos no que se refere à inclusão racial e ao desempenho de estudantes, de forma que mais universidades, por iniciativas próprias e baseadas na autonomia universitária, passaram a adotar algum tipo de política afirmativa, chegando a mais de 50 instituições de educação superior (IES) com algum tipo de acesso diferenciado como forma de política afirmativa.

$\mathrm{Na}$ Educação Básica a principal forma de estabelecimento de equidade reivindicada é a mudança curricular por meio de uma efetiva formação sobre História e Cultura AfroBrasileira e Africana, ponto que será desenvolvido com mais detalhamento a seguir.

\section{Sobre o ensino de História e Cultura Afro-Brasileira e Africana ${ }^{4}$}

No Parecer no 03/04 CNE expressa-se que o ensino de História e Cultura AfroBrasileira e Africana realizar-se-á nos diversos níveis (educação infantil, fundamental, médio e superior) e modalidades (regular, educação de jovens e adultos e educação especiall de ensino; que as diversas disciplinas devem inserir em seus conteúdos elementos de História e Cultura Afro-Brasileira e Africana; que esse ensino abrangerá o ensino de relações raciais no Brasil por meio

[...] de conceitos e de suas bases teóricas, tais como racismo, discriminações, intolerância, preconceito, estereótipo, raça, etnia, cultura, classe social, diversidade, diferença, multiculturalismo; de práticas pedagógicas, de materiais e de textos didáticos, na perspectiva da reeducação das relações étnico-raciais. (Brasil, 2004).

0 processo de formação sobre História e Cultura Afro-Brasileira e Africana e sobre Educação das Relações Étnico-Raciais tem alguns marcos que estão sempre em pauta,

4. Uma versão anterior deste tópico também foi publicada em Silva (2010). 
como já apontado anteriormente. No entanto, a aprovação de tais propostas em instituições importantes do Brasil contemporâneo tem raízes bastante anteriores. Poderia ser realizada uma genealogia das proposições que atravessasse as formulações dos movimentos negros ao longo do século XX. Dados os objetivos desse texto, a discussão será a partir da abertura política e fim da ditadura militar. 0 final dos anos 1970 foi momento de reorganização dos movimentos negros no país, mesmo momento de organização dos movimentos em prol dos direitos humanos. Nas diversas agendas desses grupos, a Educação encontrava um papel de destaque: a necessidade de desvelar elementos da História e da Cultura Afro-Brasileira e Africana. Nós, negros/as brasileiros/as, percebíamos a ausência de registros da nossa História, bem como o processo de leitura etnocêntrica e eurocêntrica da História oficializada pela escola brasileira e a constante desvalorização de formas de manifestação da nossa identidade e altivez, além da invisibilização de aspectos diversos de nossas culturas e raízes. Passou a ser cada vez mais contundente a crítica aos processos de ensino que silenciam ou omitem aspectos civilizatórios da África, as diferentes formas de contribuição de nossas nações negras (e indígenas) ancestrais para a formação do Brasil, e os registros das práticas de resistência da população afro-brasileira. As reivindicações dos movimentos negros para a Educação centravam-se sobre a necessidade de mudanças curriculares e de um efetivo ensino de História e Cultura Afro-Brasileira e Africana.

Entre os/as intelectuais e ativistas negros/as de então, destacava-se a liderança exercida por Abdias do Nascimento. No exílio, assumira a cadeira de Cultura Africana no Novo Mundo na Universidade do Estado de Nova York, Bufallo, determinando mais do que travar conhecimento com os Estudos Afro-Americanos: sendo sujeito deste processo. De volta ao Brasil, assumiu mandato de Deputado Federal e apresentou a proposta de "ação compensatória visando à implementação do princípio da isonomia social do negro". Vejamos o texto do artigo que propõe o ensino de História e Cultura Afro-Brasileira na íntegra:

Art $8^{\circ}$. 0 Ministério da Educação e Cultura, bem como as Secretarias Estaduais e Municipais de Educação, conjuntamente com representantes das entidades negras e com intelectuais negros comprovadamente engajados na matéria, estudarão e implementarão modificações nos currículos escolares e acadêmicos, em todos os níveis (primário, secundário, superior e de pós-graduação), no sentido de:

I - Incorporar ao conteúdo dos cursos de História brasileira o ensino das contribuições positivas dos africanos e seus descendentes à civilização brasileira, sua resistência contra a escravidão, sua organização e ação (a nível social, econômica e polítical através dos quilombos, sua luta contra o racismo no período pós-abolição;

II - Incorporar ao conteúdo dos cursos sobre História Geral o ensino das contribuições positivas das civilizações africanas, particularmente seus avanços tecnológicos e culturais antes da invasão europeia do continente africano; 
III - Incorporar ao conteúdo dos cursos optativos de estudos religiosos o ensino dos conceitos espirituais, filosóficos e epistemológicos das religiões de origem africana (candomblé, umbanda, macumba, xangô, tambor de mina, batuque etc.);

IV - Eliminar de todos os currículos referências ao africano como um povo apto para a escravidão', 'submisso' e outras qualificações pejorativas;

V - Eliminar a utilização de cartilhas ou livros escolares que apresentem o negro de forma preconceituosa ou estereotipada;

$\mathrm{VI}$ - Incorporar ao material de ensino primário e secundário a apresentação gráfica da família negra de maneira que a criança negra venha a se ver, a si mesma e a sua família, retratadas de maneira igualmente positiva àquela que se vê retratada a criança branca; VII - Agregar ao ensino das línguas estrangeiras europeias, em todos os níveis em que são ensinadas, o ensino de línguas africanas (yorubá ou kiswahili) em regime opcional; VIII - Incentivar e apoiar a criação de Departamentos, Centros ou Institutos de Estudos e/ou Pesquisas Africanos e Afro-Brasileiros, como parte integral e normal da estrutura universitária, particularmente nas universidades federais e estaduais. (Nascimento, 1983, p. 5.163)

0 texto do Projeto de Lei revela aspectos bastante interessantes. Primeiro, podese constatar que propostas levadas a termo atualmente - como a formação de professores/as para ensino de História e Cultura Afro-Brasileira e Africana e a estruturação de Núcleos de Estudos Afro-Brasileiros - são a concretização de uma agenda antiga. E as propostas nessa direção se renovam também nas comemorações do centenário da abolição em 1988, na Assembleia Nacional Constituinte do mesmo ano, na Marcha Zumbi dos Palmares contra o racismo, pela cidadania e a vida, em 1995, nas discussões sobre a Lei de Diretrizes e Bases da Educação nos anos que antecederam sua aprovação em 1996, nos eventos preparatórios à Conferência de Durban de 2001 e nas proposições advindas da própria Conferência. Vinte anos transcorreramse - de 1983 a 2003 - até que as proposições do PL 1.332/83 fossem finalmente aprovadas. Desse modo, somente com a Lei 10.639/03 (que modificou a LDB) e sua posterior regulamentação com o Parecer $n^{0} 03 / 04$ do CNE, iniciou-se um processo de inserção de conteúdos e de formação inicial e continuada de professores sobre História e Cultura Afro-Brasileira e Africana e sobre Educação das Relações Étnico-Raciais 5 . É bem verdade que a redação da Lei 10.639/03 seja originária do PL n 259 , apresentado em 1999 pela deputada Esther Grossi e pelo deputado Benhur Ferreira, mas a atuação anterior de Abdias do Nascimento favoreceu esse momento.

5. Ainda que possamos reconhecer mudanças em curso no que se refere ao currículo e às práticas pedagógicas, é possível também identificar que o processo de implementação da Lei 10.639/03 no interior das escolas brasileiras encontra-se em curso e necessitará mais investimento na formação inicial e continuada para os/as profissionais da educação brasileira (Gomes, 2011, p. 32). 
Na proposta original de Abdias do Nascimento, pode-se inferir a relação com os propósitos dos movimentos da Negritude e do Pan-Africanismo. Como movimento concomitantemente literário e social, na Negritude propôs-se um retorno às raízes. A ideia foi a de que a imersão nas tradições e na estética, nas produções culturais, na literatura em geral (e na poesia em particular), nas representações plásticas e na dramaturgia operasse no sentido de valorizar a tradição africana e afro-diaspórica. No caso específico da formação de professores/as para a Educação das Relações Étnico-Raciais, os objetivos transcendem aos de informar sobre o movimento literário: são também uma busca dos próprios ideais que inspiraram o movimento, tanto da expressão estética quanto dos valores e da busca de transformação social. Sobre isso, afirma Guerreiro Ramos

A negritude é uma subjetividade. Uma vivência. Um elemento passional que se acha inserido nas categorias clássicas da sociedade brasileira e que as enriquece de substância humana. Humana, demasiadamente humana é a cultura brasileira, por isso que, sem desintegrar-se, absorve as idiossincrasias espirituais, as mais variadas. A negritude, com seu sortilégio, sempre esteve presente nesta cultura, exuberante de entusiasmo, ingenuidade, paixão, sensualidade, mistério, embora só hoje por efeito de uma pressão universal esteja emergindo para a lúcida consciência de sua fisionomia. É um título de glória e de orgulho para o Brasil o de ter-se constituído no berço da negritude. (Ramos, 2003, p. 117).

As ideias do Pan-Africanismo, em grande medida elaboradas por negros/as na ou da diáspora, objetiva, de forma similar, estabelecer a África como referência fundamental para negros/as do mundo - estejam eles/as dentro ou fora do continente positivando a imagem da África, das suas tradições, histórias e diferentes aspectos das culturas. Com isso, contrapõem-se a postulações até então hegemônicas, e que ainda sobrevivem, de um continente selvagem, primitivo, atávico. A unidade dos países africanos é pensada como estrutura que mantenha a autonomia dos países por um lado e que, por outro, permita a estes mesmos uma atuação conjunta, seja no âmbito das relações internacionais, seja para a resolução de problemas comuns. 0 texto de justificativa relativo ao art. $8^{\circ}$ do $\mathrm{PL} 1.332 / 83$ é revelador:

0 conteúdo da educação recebida por aquelas crianças negras que têm oportunidade de estudar representa outro aspecto da desigualdade racial anticonstitucional na esfera da educação [...], a civilização e história dos povos africanos, dos quais descendem as crianças negras, estão ausentes do currículo escolar. A criança negra aprende apenas que seus avós foram escravos; as realizações tecnológicas e culturais africanas, sobretudo nos períodos anteriores à invasão e colonização europeia da África, são omitidas. Também se omite qualquer referência à história da heróica luta dos afro-brasileiros 
contra a escravidão e o racismo, tanto nos quilombos como através de outros meios de resistência. Comumente, o negro é retratado de forma pejorativa nos textos escolares, o que resulta na criança negra em efeitos psicológicos negativos amplamente documentados. 0 mesmo quadro tende a encorajar, na criança branca, um sentimento de superioridade em relação ao negro. 0 art. $8^{\circ}$ deste projeto de lei objetiva a correção desta anomalia e a implementação do direito à isonomia assegurada pela constituição. (Nascimento, 1983).

A argumentação é explícita. Trata-se de estabelecer a oportunidade ao alunado brasileiro de obter informações e reconhecer elementos da complexidade do continente de origem de metade (pelo menos) de nossa população; de estabelecer "lugares de memória" (Nora apud King, 1996, p. 77) sobre o passado africano; de possibilitar a identificação positiva dos/as alunos/as negros/as brasileiros/as com aspectos de seu passado; de possibilitar aos/às estudantes de todas as cores reconhecerem a diversidade e complexidade do continente africano e as profundas contribuições das populações africanas para a humanidade.

A percepção tem sido de que ideias restritivas e manipuladas sobre a História e as tradições africanas e afro-brasileiras, sistematicamente difundidas pela escola em currículos e livros didáticos (que operam tanto por informações restritivas ou equivocadas quanto pela omissão), atuam para criar nos/as alunos/as uma predisposição à hierarquia racial. Importante observar que a proposta do estudo das contribuições africanas relaciona-se com a estruturação da identidade da população negra brasileira (Munanga, 2004; Munanga; Gomes, 2006), bem como da sociedade como um todo.

0 movimento de apagar os lugares de memória das matrizes africanas no Brasil foi bastante efetivo, de forma que a colonização cultural operou e ainda opera em diferentes níveis em todos/as nós, manifestando-se em hipervalorização de tradições europeias e desvalorização de aspectos da cultura de matriz africana. Possivelmente em função disso o trabalho de formação de professores/as é uma tarefa zumbíleab', pois na nossa formação escolar, educacional e cultural, as informações mais simplórias sobre nosso passado africano foram sistematicamente negadas ou substituídas por informações estereotipadas. Estamos, portanto, num movimento inicial de descoberta da riqueza, da pluralidade, dos valores, do desenvolvimento tecnológico, do alto desenvolvimento social, de um sem fim de aspectos civilizatórios de nossos/as antepassados/as africanos/as e africanos/as da diáspora.

Para a compreensão desse processo na educação, é caro o conceito de "alfabetismo da diáspora", tal como formulado por Joyce King (1996), com o sentido de conhecimento

6. Termo que emprestamos de Edna Roland, então Coordenadora da Área de Combate ao Racismo e Discriminação da UNESCO no Brasil (2006). 
e ressignificação da "nossa história", da história do povo negro na diáspora. Este alfabetismo consiste na aprendizagem da leitura de signos culturais das heranças africanas para além das distorções, da parcialidade e das ausências determinadas pela hegemonia cultural e por séculos de dominação. 0 sentido de alfabetismo é de processo inicial e provisório. A luta contra a discriminação racial que percorreu o século XX deparou-se com diversos processos de racialização, entre os quais o estabelecimento de conceitos e formas de compreensão distorcidos e restritivos sobre a tradição africana e afro-brasileira. As proposições do racismo científico, para além de sua rejeição após a Segunda Guerra Mundial, conformaram operadores importantes no campo simbólico, e em geral se mantêm. 0 conceito de alfabetização da diáspora é significativo pela sua proposta de que nós, que fomos educados/as numa lógica eurocêntrica, devemos nos alfabetizar, recolher conhecimentos básicos sobre nossa origem africana e sobre toda a produção cultural e histórica dos povos africanos da diáspora.

Tal proposta coaduna-se com um dos objetivos estratégicos do PNDH III cujas ações programáticas apontam, entre outras, a necessidade de: “h) Fomentar programas de valorização do patrimônio cultural das populações negras; i) Assegurar o resgate da memória das populações negras, mediante a publicação da história de resistência e resgate de tradições das populações das diásporas" (Brasil, 2010, p. 88). Interpretamos que o processo de estruturação dos programas nacionais de direitos humanos, em especial o terceiro, de forma dialogada com movimentos sociais e movimentos negros, tem inserido proposições dos mesmos no centro do debate e na busca de alternativas de atuação.

Em 2009 foi aprovado o Plano Nacional de Implementação das Diretrizes Curriculares Nacionais para Educação das Relações Étnico-Raciais e para o Ensino de História e Cultura Afro-Brasileira e Africana, outro importante documento de apoio aos sistemas de ensino. 0 Plano Nacional está dividido em duas partes. Na primeira, apresenta as atribuições institucionais: do MEC, dos sistemas de ensino (nos níveis federal, estadual e municipal), dos conselhos de educação, das instituições de ensino (escolas), dos Fóruns de Diversidade e dos Núcleos de Estudos Afro-Brasileiros das universidades. Na segunda parte apresenta as ações principais a serem desenvolvidas na educação infantil, ensino fundamental, ensino médio, educação superior, e também na educação de jovens e adultos, educação tecnológica e formação profissional e, finalmente, educação em áreas remanescentes de quilombos. 


\section{Palavras finais}

Este artigo trouxe algumas informações sobre o projeto em curso no Brasil de uma Educação das Relações Étnico-Raciais inserida numa perspectiva ampla e crítica de Educação em Direitos Humanos. Crítica significa que considera as desigualdades raciais (e as de gênero, de orientação sexual, de identidade de gênero, de classe social, de idadel como estruturais e estruturantes nessa sociedade contemporânea. Crítica tem também o sentido de identificar e denunciar ataques aos direitos humanos, os quais vitimam a população negra, sobretudo aquela inserida em espaços de resistência como nas comunidades remanescentes de quilombos e nos terreiros. Outrossim, crítica é evidenciar, nas políticas públicas, a constante necessidade de considerar os indicadores de desemprego, homicídios, miserabilidade, vulnerabilidade, sexismo e outros que atingem diretamente esse grupo social.

As contribuições possíveis por parte da educação são de mudanças na lógica excludente das instituições escolares. Um ponto central seria uma reorganização dos currículos escolares em uma perspectiva multicultural, implantando uma educação aberta para o diálogo constante sobre e com as diferenças. Em função desse ponto de vista, o artigo buscou a interlocução com normativas que foram organizadas de forma aberta para a efetiva participação dos movimentos sociais, como são os casos dos programas de direitos humanos e das diversas conferências, tanto as nacionais quanto a mundial. Logo, estudar e conhecer esses documentos pode ser exercitar o diálogo com os movimentos sociais que participaram dos processos de definição das suas prioridades.

De forma geral, a documentação é vasta e as proposições são contrastantes com um contexto em que as violações dos direitos são rotineiras nas relações sociais. 0 desafio, então, é romper com tais violações e estruturar, de forma coletiva e participativa, escolas que operem para a promoção de igualdade étnico-racial. Uma possibilidade para a Educação em Direitos Humanos é operar numa perspectiva que compreenda e busque superar as desigualdades raciais (e as de gênero, de orientação sexual e de identidade de gênerol e que priorize a interlocução com movimentos sociais.

0 exame das normativas em vigor, relativas a Direitos Humanos e Educação em Direitos Humanos, desvenda amplo leque de proposições que revelam possibilidades de articulação em prol da promoção da igualdade racial. 


\section{Referências}

APPLE, Michael. Consumindo o outro: branquidade, educação e batatas fritas baratas. In: COSTA, Marisa (Org.) Escola básica na virada do século: cultura, política e educação. São Paulo: Cortez, 1996. p. 25-43.

APPLE, Michael. Políticas de direita e branquidade: a presença ausente da raça nas reformas educacionais. Revista Brasileira de Educação, São Paulo, n. 16, p. 61-67, jan.-abr. 2001.

BALBO, Laura; MANCONI, Luigi. Razzismi: un vocabolario. Milano: Feltrinelli, 1993.

BEM, Arim. Educação e reprodução do racismo: as armadilhas dos modelos alternativos. Educação e Sociedade, v. 14, n. 44, p. 96-110, abr. 1993.

BRASIL. Programa Nacional de Direitos Humanos. Brasília: Presidência da República; Ministério da Justiça, 1996.

Relatório do Comitê Nacional para a Preparação da Participação Brasileira na III Conferência Mundial das Nações Unidas contra o Racismo, Discriminação Racial, Xenofobia e Intolerância Correlata. Brasília: Ministério da Justiça, 2001.

Programa Nacional de Direitos Humanos - PNDH II. Brasília: Presidência da República; Ministério da Justiça, 2002.

A Fundação Cultural Palmares na IIl Conferência Mundial de Combate ao Racismo, Discriminação Racial, Xenofobia e Intolerância correlata. Organização de Carlos Moura e Jônatas Barreto. Brasília: Fundação Cultural Palmares, 2002.

Lei Federal no 10.639/03. Brasília: 2004.

BRASIL. Ministério da Educação (MEC). Conselho Nacional de Educação (CNE). Parecer nº 03/2004 de 10 de março do Conselho Pleno do CNE. Brasília: MEC; SEPPIR, 2004.

I Conferência Nacional de Promoção da Igualdade Racial: Brasília, 30 de junho a 2 de julho de 2005. Relatório Final. Brasília: Secretaria Especial de Políticas de Promoção da Igualdade Racial (SEPPIR), 2005.

Plano Nacional de Educação em Direitos Humanos. Comitê Nacional de Educação em Direitos Humanos. Brasília: Secretaria Especial dos Direitos Humanos, 2006.

Relatório de gestão 2003-2006. Brasília: SEPPIR, 2007.

Lei Federal n. 10.645/08. Brasília: 2008.

. Documento Final da I Conferência de Educação Escolar Indígena. Brasília: MEC; FUNAI, $2009 a$.

Plano Nacional de Implementação das Diretrizes Curriculares Nacionais para Educação das Relações Etnicorraciais e para o Ensino de História e Cultura Afrobrasileira e Africana. Brasília, MEC, 2009b.

. Documento Final da Conferência Nacional de Educação. Brasília: MEC, 2010.

Programa Nacional de Direitos Humanos (PNDH-3). Secretaria de Direitos Humanos da

Presidência da República. rev. e atual., Brasília: SDH/PR, 2010 
Estatuto da Igualdade Racial (Lei no 12.288/2010). Disponível em: <http://www.planalto.gov.br/ ccivil_03/_Ato2007-2010/2010/Lei/L12288.htm>. Acesso em: 25 agosto 2011.

COETZEE, J. M.. Le origini ideologiche dell'apartheid: emergere dalla censura. Trad. Angela Righetti. Verona: Università, 1999.

DAL LAGO, Alessandro. Non-persone: L'esclusione dei migranti in una società globale. Milano: Feltrinelli, 1999.

FERNANDES, Florestan. A integração do negro na sociedade de classes. São Paulo: USP, 1964.

GIROUX, Henry. Redefinindo as fronteiras da raça e etnicidade: além da política do pluralismo. In: GIROUX, Henry. Cruzando as fronteiras do discurso educacional: novas políticas em educação. Porto Alegre: Artes Médicas Sul, 1999. p. 133-172.

GOMES, Nilma Lino. As práticas pedagógicas com as relações étnico-raciais nas escolas públicas: desafios e perspectivas. In: . (Org.). Práticas pedagógicas de trabalho com relações étnicoraciais na escola na perspectiva da Lei no 10.639/03. Brasília: SECADI/MEC; UNESC0, 2011 (no prelo). HARRIS, Leonard (Org.). Racism: key concepts in critical theory. New York: Humanity Books, 1999. JOHLER, Reinhard. Mir parlen italiano: la costruzione sociale del pregiudizio etnico: storia dei trentini nel Vorarlberg. Trento: Museo storico, 1996.

KING, Joyce. A passagem média revisitada: a educação para a liberdade humana e a crítica epistemológica feita pelos Estudos Negros. In: SILVA, Luiz; AZEVEDO, José; SANTOS, Edmilson (Org.). Reestruturação curricular: novos mapas culturais, novas perspectivas educacionais. Porto Alegre: Sulina, 1996. p. 75-101.

LEITE, Ilka Boaventura. 0 projeto político quilombola: desafios, conquistas e impasses atuais. Estudos Feministas, Florianópolis, v. 16, n. 3, p. 965-977, set.-dez. 2008.

MCLAREN, Peter. Multiculturalismo crítico. São Paulo: Cortez, 1997.

MORRISON, Toni. Black Matters In: ESSED, Philomena; GOLBERG, David (Org.). Race critical theories, text and context. Malden: Blackwell, 2002. p. 265-282.

MUNANGA, Kabengele; GOMES, Nilma. O negro no Brasil de Hoje. São Paulo: Global, 2006.

MUNANGA, Kabengele. Rediscutindo a mestiçagem no Brasil: identidade nacional versus identidade negra. Belo Horizonte: Autêntica, 2004.

NASCIMENTO, Abdias. Projeto de Lei n. 1.332 de 1983. Diário do Congresso Nacional. Brasília: Câmara dos Deputados, 15 de junho de 1983, p. 5162-5165.

o Brasil na mira do Pan-Africanismo. Salvador: EDUFBA; CEAO, 2002.

ONU. Declaração e Programa de Ação adotados na III Conferência Mundial de Combate ao Racismo, Discriminação Racial, Discriminação Racial, Xenofobia e Intolerância Correlata. 31 de agosto a 8 de setembro de 2001, Durban - África do Sul.

QUILOMBO: vida, problemas e aspiração do negro. Edição Fac-similar do jornal dirigido por Abdias do Nascimento. São Paulo: Fundação de Apoio à Universidade de São Paulo: Ed. 34, 2003.

PIOVESAN, Flávia. Ações afirmativas da perspectiva dos Direitos Humanos. Cadernos de Pesquisa, v. 35, n. 124, p. 43-55, jan.-abr. 2005. 
RAMOS, Alberto Guerreiro. Apresentação da negritude. Quilombo, v. 2, n. 10, p. 11, jun.-jul. 1950. In: NASCIMENTO, Abdias. Edição fac-similar do jornal Quilombo. São Paulo: Fundação de Apoio à Universidade de São Paulo; Ed. 34, 2003. p. 117.

0 problema do negro na sociologia brasileira. Cadernos do Nosso Tempo, v. 2, jan.-jun. 1954.

SILVA, Paulo Vinícius Baptista da. A formação docente sob a ótica dos Direitos Humanos: diversidades etnicorraciais. In: FERREIRA, Lúcia de Fátima Guerra; ZENAIDE, Maria de Nazaré Tavares; DIAS, Adelaide Alves (Org.). Direitos Humanos na Educação Superior: Subsídios para a Educação em Direitos Humanos na Pedagogia. João Pessoa: Editora Universitária da UFPB, 2010. p. 277-310.

SILVÉRIO, Valter Roberto. Políticas Raciais Compensatórias: O Dilema Brasileiro do Século XXI. In: SABOIA, Gilberto V.; GUIMARÃES, Samuel P. (Org.) Anais dos Seminários Preparatórios para Conferência Mundial contra o racismo, discriminação racial, xenofobia e intolerância correlata. Brasília: Secretaria de Estado de Direitos Humanos, 2001. p. 123-138.

TELLES, Edward E. Racismo à brasileira: uma nova perspectiva sociológica. Rio de Janeiro: Relumé Dumará; Fundação Ford, 2003.

WIEVIORKA, Michel. El espacio del racismo. Barcelona: Paidós, 1992.

Recebida $1^{\text {a }}$ versão em agosto de 2011

Aprovada $2^{\mathrm{a}}$ versão em novembro de 2011

Paulo Vinicius Baptista da Silva, doutor em Psicologia (Psicologia Social) pela Pontifícia Universidade Católica de São Paulo. É professor do Programa de Pós-Graduação em Educação da Universidade Federal do Paraná, exercendo atualmente a função de coordenador. Coordena o Núcleo de Estudos Afro-Brasileiros (NEAB-UFPR), é bolsista de produtividade em pesquisa do CNPQ, vice-coordenador do Grupo de Trabalho Educação e Relações Raciais da ANPED e representante da Região Sul na diretoria da Associação Brasileira de Pesquisadores Negros(as) (ABPN). Publicação recente: Racial Inequalities in the Symbolic Realm: The Brazilian Context (Revue Canadienne d'Études du Développement, v. 29, p. 245-266. 2010). E-mail: paulovbsilvaAuol.com

Débora Cristina de Araújo, doutoranda em Educação no Programa de Pós-Graduação em Educação da Universidade Federal do Paraná na linha de Políticas Educacionais. É professora da rede estadual do Paraná. Desenvolve pesquisa sobre diversidade étnico-racial no Programa Nacional de Biblioteca da Escola. Tem atuado também em estudos sobre relações raciais, literatura infantojuvenil e racismo discursivo. E-mail: debbora.åhotmail.com 